\title{
A New Putative Chitinase from Reticulitermes speratus KMT001 ${ }^{1}$
}

\author{
Youngseok $\mathrm{Ham}^{2} \cdot$ Han-Saem Park ${ }^{2}$ - Yeong-Suk Kim ${ }^{2}$ Tae-Jong Kim $\mathbb{D}^{2, \dagger}$
}

\begin{abstract}
Termites are pests that cause serious economic and cultural damage by digesting wood cellulose. Termites are arthropods and have an epidermis surrounded by a chitin layer. To maintain a healthy epidermis, termites have chitinase $(\beta$ -1,4-poly-N-acetyl glucosamidinase, EC 3.2.1.14), an enzyme that hydrolyzes the $\beta-1,4$ bond of chitin. In this study, the amino acid sequence of the gene, which is presumed to be termite chitinolytic enzyme (NCBI accession no. KC477099), was obtained from a transcriptomic analysis of Reticulitermes speratus KMT001 in Bukhan Mountain, Korea. An NCBI protein BLAST search confirmed that the protein is a glycoside hydrolase family 18 (GH18). The highest homology value found was 47\%, with a chitinase from Araneus ventricosus. Phylogenetic analysis indicated that the KC477099 protein has the same origins as those of arthropods but has a very low similarity with other arthropod chitinases, resulting in separation at an early stage of evolution. The KC477099 protein contains two conserved motifs, which encode the general enzymatic characteristics of the GH18 group. The amino acid sequences Asp ${ }^{156}-\operatorname{Trp}^{157}$-Glu ${ }^{158}$, which play an important role in the enzymatic activity of the GH18 group, were also present. This study suggests that the termite KC477099 protein is a new type of chitinase, which is evolutionarily distant from other insect chitinases.
\end{abstract}

Keywords: termite, Reticulitermes speratus KMT001, phylogenetic analysis, chitinase

\section{INTRODUCTION}

Chitin is an amino sugar in which N-acetyl-Dglucose-2-amine is polymerized by $\beta-1,4$ bonds (Aronson et al., 1997; Bussink et al., 2007; Han et al., 2005). It is found in the eggshells of nematodes (Brydon et al., 1987) and cell walls of fungi (Bartnicki-Garcia, 1968) and comprises the skeleton of the shells of arthropods (Kramer and Koga, 1986). Chitinase ( $\beta$-1,4-poly-N-acetyl glucosaminidase, EC 3.2.1.14) is an enzyme that hydrolyzes the $\beta-1,4$ bonds of chitin (Henrissat and Davies, 1997; Kramer and Koga, 1986) and belongs to the glycoside hydrolase family 18 (GH18) (Reynolds and Samuels, 1996). Chitinase has a wide range of functions in organisms as diverse as insects, bacteria, fungi, plants, and animals. Insects use chitinase to decompose old cuticle layers for the synthesis and reconstitution of new cuticle layers during ecdysis in the growth process (Henrissat and Davies, 1997; Merzendorfer and Zimoch, 2003). Chitinases are also found in organisms that do not have chitin. These enzymes protect plants from pathogenic fungi

\footnotetext{
${ }^{1}$ Date Received March 19, 2019, Date Accepted May 13, 2019

2 Department of Forest Products and Biotechnology, Kookmin University, Seoul 02707, Republic of Korea

† Corresponding author: Tae-Jong Kim (e-mail: bigbell@kookmin.ac.kr, ORCID: 0000-0002-7483-0432)
} 
(Badariotti et al., 2007; Taira et al., 2002). Chitinases in some bacteria and animals decompose chitin in food to produce nutrients, or they may be used to defend against external chitin toxicity (Guan et al., 2011; Kawada et al., 2007; Renkema et al., 1998; van Eijk et al., 2005).

GH18 has eight similar $\alpha / \beta$-barrel structures and two conserved regions, which play an important role in enzymatic activity. All structure and regions are located on the $\beta 3$ and $\beta 4$ strands (Cho et al., 2010; Fukamizo, 2000; Henrissat and Bairoch, 1993; Korb et al., 2012; Kramer and Muthukrishnan, 1997; Sharma et al., 2011). Of the two conserved domains, domain II, which is located on the $\beta 4$ strand and includes acidic amino acids, such as aspartic and glutamic acids, is known to play an important role in enzymatic activity (Lu et al., 2002; Terwisscha van Scheltinga et al., 1996; Thomas et al., 2000).

Termites are insects belonging to the order Blattodea and are known as pests that damage wooden buildings by degrading cellulose (Matsui et al., 2009). Termites may ingest chitin while eating wood infested with fungi (Mishra and Sensarma, 1981). The amount and activity of chitinases in the digestive tract of insects were observed to be increased when chitinous foods were ingested (Fukamizo et al., 1985; Liu et al., 2013; Merzendorfer and Zimoch, 2003). Efforts to combat termites using chemicals have been made (Hadi et al., 2018; Kim and Chung, 2017; Mun and Nicholas, 2017). Previous studies suggest the use of chemicals that inhibit chitin synthesis as insecticides (Sandoval-Mojica and Scharf, 2016; Zhu et al., 2016). Pentoxifylline, an inhibitor of chitinases, was shown to kill termites (Husen and Kamble, 2013; Husen et al., 2015). According to our research results, no reports on the chitinases of termites are available until now. In this study, a gene that encodes a putative chitinase was obtained from a transcriptomic analysis of Reticulitermes speratus in Bukhan Mountain, Seoul, Korea. By using the amino acid sequence, its taxonomic position was identified through phylogenetic analysis, and the amino acid sequences, which are an important motif in GH18, were compared using multiple sequence alignment.

\section{MATERIALS and METHODS}

\subsection{Termites}

The termites used were $R$. speratus KMT001 (Cho et al., 2010), which were collected in the Bukhan Mountain, Seoul, Korea (latitude: 37.614009, longitude: $126.990545)$. The termites were grown at $26^{\circ} \mathrm{C}$ and $70 \%$ humidity without light.

\subsection{Chitinase genes of $R$. speratus KMT001}

A putative chitinase gene was selected using transcriptomic analysis from previous studies (Park et al., 2014) aimed at elucidating its biological function. The amino acid sequence, including the open reading frame (ORF), was inferred from the selected gene sequence. The chitinase gene identified from $R$. speratus KMT001 was registered in the NCBI database (accession number: KC477099).

\subsection{Phylogenetic analysis of the putative chitinase}

A protein BLAST search (http://blast.ncbi.nlm.nih. gov/) was performed on the NCBI website using the amino acid sequence of the putative chitinase to identify homologous genes. For the multiple sequence alignment and phylogenetic analysis, we selected the gene with the highest homology score from each genus among 100 homologous sequences. The putative chitinase sequence in this study and 19 homologous sequences were aligned using ClustalW in the MEGA4 program (https://www.megasoftware.net/mega4/). For the phylo- 
genetic analysis of the aligned amino acid sequences, a neighbor-joining method was used to assess the evolutionary distance using bootstrap and crossvalidation methods with 1,000 replications to estimate the reliability of the results (Nei and Saitou, 1987; Tamura et al., 2007).

\section{RESULTS and DISCUSSION}

\subsection{Putative chitinases of $R$. speratus KMTO01}

A previous transcriptomic analysis of $R$. speratus KMT001 using the GS FLX System (Park et al., 2014) provided sequence information for the expressed mRNA.
Among the genes whose biological functions were suggested, two contigs (contig00176 and contig 03679) and 17 singletons, which appear to be chitinases, were selected (Table 1). The biological function analysis of contig00176 (NCBI accession number: KC477099) indicated that the closest gene in the NCBI database was a chitinase of Araneus ventricosus, a spider. The gene was $1,300 \mathrm{bp}$ in length, and the complete ORF of the putative chitinase was 1,199 bp. The most similar gene to contig03679 in the NCBI database was a chitinase from Ixodes scapularis, a mite subspecies. In contig03679, only an ORF with a short base sequence, $178 \mathrm{bp}$, could be identified. The other 17 singletons did not have an identifiable ORF and were excluded from this study.

Table 1. Putative chitinase genes from transcriptomic analysis of $R$. speratus KMT001.

\begin{tabular}{|c|c|c|}
\hline Identification name & $\begin{array}{l}\text { Strains that } \\
\text { have the closest gene }\end{array}$ & $\begin{array}{l}\text { Length of sequence } \\
\text { (base pair) }\end{array}$ \\
\hline \multicolumn{3}{|l|}{ (Assembled sequences) } \\
\hline Contig00176 & Araneus ventricosus & 1300 \\
\hline Contig03679 & Ixodes scapularis & 178 \\
\hline \multicolumn{3}{|l|}{ (Singleton sequences) } \\
\hline GEKBKKN03C2OJA & Beta vulgaris subsp. Vulgaris & 456 \\
\hline GEKBKKNO3DGRNH & Culex quinquefasciatus & 137 \\
\hline GEKBKKN04EANL5 & Clostridium phytofermentans & 504 \\
\hline GEKBKKN04EBH72 & Nasonia vitripennis & 391 \\
\hline GEKBKKN04EC1T3 & Clostridium sp. & 489 \\
\hline GEKBKKN04EGXG0 & Listeria seeligeri & 394 \\
\hline GEKBKKN04EH9RU & Anopheles gambiae & 389 \\
\hline GEKBKKN04EMBYY & Clostridium botulinum & 438 \\
\hline GEKBKKN04ENHY3 & Listeria welshimeri & 390 \\
\hline GEKBKKN04ENU5M & Clostridium sp. & 457 \\
\hline GEKBKKN04EPUMP & Ostrinia furnacalis & 462 \\
\hline GEKBKKN04EQ9DU & Clostridium botulinum & 488 \\
\hline GEKBKKN04ER1D0 & Clostridium paraputrificum & 411 \\
\hline GEKBKKN04ETLU4 & Clostridium botulinum & 354 \\
\hline GEKBKKN04EUAMJ & Clostridium paraputrificum & 362 \\
\hline GEKBKKN04EULGE & Clostridium sp. & 358 \\
\hline GEKBKKN04EZ9ET & Nasonia vitripennis & 487 \\
\hline
\end{tabular}




\subsection{Identification of homologous genes using protein BLAST}

We searched for genes homologous to the ORF KC477099 in the NCBI database using a protein BLAST search at the National Center for Biotechnology Information (Table 2). The 100 most similar genes were from GH18, distributed over in 19 orders. Among the search results, none were found in the order Blattodea, to which $R$. speratus belongs. The highest homology with KC477099 was AAN39100 from A. ventricosus with an e-value of 7E-112. In addition to chitinase, chitotriosidase and acidic mammalian chitinase (AMCase), which belong to the same GH18 group, were found to have high homology scores with KC477099.

The orders Decapoda, Diptera, and Mesostigmata in the phylum Arthropoda have homologous chitinase genes in the GH18 group. Members of the class Enteropneusta in the phylum Hemichordata, order Ostreoida in the phyla Mollusca, Rodentia, Perissodactyla, Carnivora, Primates, Squamata, Dasyuromorphia, and Diptera have genes for chitotriosidase and AMCase in GH18 (Bussink et al., 2007; Reardon and Farber, 1995). Homologous chitinase genes have been identified in various animals. Previous studies suggest that AMCase and chitotriosidase in insects, bacteria, and plants are highly homologous to chitinase (Arakane and Muthukrishnan, 2010; Henrissat, 1999). The role of chitinase in non-insect animals and plants is different from that in insects that have a chitin exoskeleton. Chitinase in the former is used for the digestion of chitin for nutrients or as a defense mechanism against insects,

Table 2. Results of TBLASTN searches using the amino acid sequence of KC477099 (contig00176) ORF from $R$. speratus KMT001.

\begin{tabular}{|c|c|c|c|c|}
\hline $\begin{array}{l}\text { Accession no. } \\
\text { in NCBI }\end{array}$ & Species & Common name & $\begin{array}{c}\text { Query coverage (\%) / } \\
\text { Identities (\%) }\end{array}$ & E-value \\
\hline AAN39100 & Araneus ventricosus & Spider & $91 / 47$ & $7 \mathrm{E}-112$ \\
\hline EFN88161 & Harpegnathos saltator & Ant & $90 / 47$ & $6 \mathrm{E}-110$ \\
\hline XP_003739697 & Galendromus occidentalis & Mite & 99 / 44 & 9E-109 \\
\hline ACR23315 & Penaeus vannamei & Shrimp & $90 / 47$ & $1 \mathrm{E}-106$ \\
\hline XP_002413492 & Ixodes scapularis & Tick & $97 / 43$ & 2E-102 \\
\hline XP_002597592 & Branchiostoma floridae & Lancelet & $97 / 43$ & 2E-99 \\
\hline EHJ70785 & Danaus plexippus & Butterfly & $97 / 41$ & 2E-97 \\
\hline XP_001959669 & Drosophila. ananassae & Fly & $96 / 42$ & $5 \mathrm{E}-97$ \\
\hline EFX90412 & Daphnia pulex & Water flea & $94 / 42$ & $4 \mathrm{E}-96$ \\
\hline XP_970191 & Tribolium castaneum & Beetle & $92 / 42$ & 3E-95 \\
\hline EKC38802 & Crassostrea gigas & Oyster & $90 / 44$ & 5E-94 \\
\hline XP_002740150 & Saccoglossus kowalevskii & Acorn worm & $93 / 41$ & $4 \mathrm{E}-94$ \\
\hline NP_997469 & Rattus norvegicus & Rat & $90 / 40$ & $6 \mathrm{E}-93$ \\
\hline NP_001137269 & Equus caballus & Horse & $88 / 42$ & $1 \mathrm{E}-92$ \\
\hline XP_003999521 & Felis catus & Cat & $88 / 42$ & $1 \mathrm{E}-91$ \\
\hline XP_514112 & Pan troglodytes & Chimpanzee & $90 / 41$ & 2E-91 \\
\hline XP_003220370 & Anolis carolinensis & Lizard & $90 / 39$ & 8E-91 \\
\hline XP_003769823 & Sarcophilus harrisii & Tasmanian devil & $90 / 39$ & $1 \mathrm{E}-89$ \\
\hline XP_001372881 & Monodelphis domestica & Opossum & $90 / 39$ & 2E-89 \\
\hline
\end{tabular}


but the latter is mainly used for the maintenance of the chitin exoskeleton (Rathore and Gupta, 2015). The results of this study confirm that AMCase and chitotriosidase have high homology scores with chitinases found in insects, bacteria, and plants (Rathore and Gupta, 2015). Hypothetical proteins from Amphoxiformes, Cladocera, Diptera, and Coleoptera have a conserved region, but the active sites of GH18 and their activities remain to be confirmed.

\subsection{Multiple sequence alignment of KC477099}

To compare the amino acid sequences of KC477099, one amino acid sequence with the highest homology score in each of the 19 orders among the 100 homologous sequences was selected, and multiple sequence alignments were performed using ClustalW in the MEGA4 program (Fig. 1). KC477099 shared two conserved regions (motifs I and II in Fig. 1) and an $\beta 1$

$\begin{array}{lrl}\text { KC477099 } & 36 & \text { VVCYYGSWATYR } \\ \text { XP_003220370 } & 24 & \text { LSCYFTNWGQYR } \\ \text { XP_001372881 } & 24 & \text { LTCYFTNWAQYR } \\ \text { XP_003769823 } & 24 & \text { LTCYFTNWAQYR } \\ \text { NP_997469 } & 24 & \text { LVCYFTNWAQYR } \\ \text { NP_001137269 } & 24 & \text { LVCYFTNWAQYR } \\ \text { XP_003999521 } & 24 & \text { LVCYFTNWAQYR } \\ \text { XP_5144112 } & 34 & \text { LVCYFTNWAQYR } \\ \text { XP_002740150 } & 27 & \text { RVCYYSNWAQYR } \\ \text { XI_002597592 } & 29 & \text { RVCYHTNWSQYR } \\ \text { EKC38802 } & 23 & \text { RVCYYTNWSQYR } \\ \text { XP_001959669 } & 32 & \text { VVCYQGTWSTYR } \\ \text { EHJ70785 } & 27 & \text { VICYHGTWATYR } \\ \text { XP_002413492 } & 68 & \text { FICYWGSWSHYR } \\ \text { XP_970191 } & 34 & \text { VVCYLGTWSVYR } \\ \text { EFX90412 } & 33 & \text { MVCYYGSWAVYR } \\ \text { ACR23315 } & 1 & \text { MVYYYGSWAVYR } \\ \text { AAN39100 } & 31 & \text { VVCYLGSWANYR } \\ \text { XP_003739697 } & 34 & \text { VVCYYGSWAVYR } \\ \text { EFN88161 } & 32 & \text { IVCYYGSWAVYR } \\ & & \text { * * }\end{array}$

$\beta 5$

$\begin{array}{lll}\text { KC477099 } & 190 & \text { MLTVAVCAD } \\ \text { XP_003220370 } & 179 & \text { MVTAAVAAG } \\ \text { XP_001372881 } & 179 & \text { MVTAAVAAG } \\ \text { XP_003769823 } & 179 & \text { MVTAAVAAG } \\ \text { NP_997469 } & 179 & \text { MVTAAVAAG } \\ \text { NP_001137269 } & 179 & \text { LLSAAVPAG } \\ \text { XP_003999521 } & 179 & \text { LLSAAVPAG } \\ \text { XP_5144112 } & 189 & \text { LLSAAVPAG } \\ \text { XP_002740150 } & 189 & \text { LLTAAVAAG } \\ \text { XP-002597592 } & 189 & \text { LLTAAIPAG } \\ \text { EKC38802 } & 177 & \text { MLSAAVPAG } \\ \text { XP_001959669 } & 188 & \text { ILTAAVGSA } \\ \text { EHJ70785 } & 182 & \text { ILSAAVAAV } \\ \text { XP_002413492 } & 223 & \text { LLTAAVSAG } \\ \text { XP_970191 } & 191 & \text { LLTAAFGAG } \\ \text { EFX90412 } & 189 & \text { LLTAAVSPG } \\ \text { ACR23315 } & 158 & \text { MLTAAVSAG } \\ \text { AAN39100 } & 186 & \text { LLSAAVSAG } \\ \text { XP_003739697 } & 191 & \text { LLTAAVSAG } \\ \text { EFN88161 } & 188 & \text { ILSAAVGAA } \\ & & \end{array}$

$\beta 2$

63 CTHIVYSFMGLE 51 CTHLIYAFAGMT 51 CTHLIYAFAGMS 51 CTHLIYAFAGMR 51 CTHLIYAFAGMQ 51 CTHLIYAFAGMN 51 CTHLIYAEAGMT 61 CTHLIYAFAGMT 54 CTHIVYAFANM 56 CTHIIYSFAKMT 50 CTHVIYAFAKMN 57 CTHLIYAFLGIE 51 CTHIVYGFMGIN 95 CTHLVYTFAKLE 61 CTHIVYSEAGLD 60 CTHIIYGFTGLG 28 CTHLIYGFAGLK 58 CTHVIYGFAKLS 61 CTHLIYGFAGLG 59 CTHLIYTFVGIS

$\beta 6$

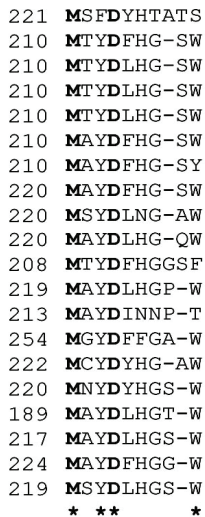

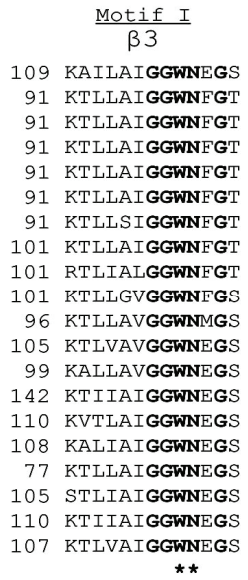

$\beta 7$

271 KLIMGIPLYGR 259 KLIVGEPTYGH 259 KLIVGFPSYGH 259 KLIVGEPSYGH 259 KLIVGFPEYGH 259 KLILGMPTYGR 259 KLILGMPAYGR 269 KLILGMPTYGR 269 KLIVGMPTYGR 269 KINLGMGLYGR 258 KINLGMPLYGR 272 KLVLGVPEYGR 267 KLVLGLPEYGH 303 KLVLGLPLYGR 264 KLVLGVPLYGR 272 KIIMGMPLYGR 239 KLVLGIGLYGR 266 KVILGMGTYGR 271 KIILGMGLYGR 268 KIVVGVPFYGR

$\begin{array}{ll} & \frac{\text { MOtif II }}{\beta 4} \\ 150 & \text { FDGLDIDWEYP } \\ 132 & \text { FDGLDFDWEYP } \\ 132 & \text { FDGLDFDWEYP } \\ 132 & \text { FDGLDFDWEYP } \\ 132 & \text { FDGLDLDWEYP } \\ 132 & \text { FDGLDLDWEYP } \\ 132 & \text { FDGLDLDWEYP } \\ 142 & \text { FDGLDLDWEYP } \\ 142 & \text { FDGEDVDWEYP } \\ 142 & \text { FDGLDLDWEYP } \\ 137 & \text { FDGLDMDWEYP } \\ 146 & \text { FDGLDLDWEYP } \\ 140 & \text { FDGLDIDWEYP } \\ 173 & \text { FDGLDMDWEYP } \\ 151 & \text { FDGLDLDWE } \\ 149 & \text { FDGLDFDWEYP } \\ 118 & \text { FDGLDLDWEYP } \\ 146 & \text { FDGLDMDWEYP } \\ 151 & \text { FDGLDMDWEYP } \\ 148 & \text { FDGEDLDWEYP } \\ & \text { * ** }\end{array}$

$\beta 8$

365 GTMMWALESEDE 356 GAMVWSLDLDDF 356 GAMVWAIDLDDF 356 GAMVWAIDLDDE 356 GAMIWAIDLDDE 354 GAMVWALDMDDE 354 GAMVWALDMDDE 364 GAMVWALDLDDF 365 GTMVWAMDLDDE 364 GAMVWALDTDDE 356 GIMVWALDLDDF 370 GIMIWSLESDDE 355 GAMIWSIETDDE 401 GIMVWSIETDDE 370 GIMVWSIDTDDF 370 GALTWSIETDDE 336 GAMVWS IETDDF 361 GGMIWSLETDDF 369 GGMVWSIETDDF 374 GVMLWSVETDDF

Fig. 1. Multiple amino acid sequence alignment of KC477099 from R. speratus KMT001 and chitinase from 19 strains obtained from a protein BLAST search of the National Center for Biotechnology Information. Motifs I and II are indicated on the top of the alignments. The bold characteristics indicate the consensus sequences in the active sites of GH18. The star marks on the bottom of the alignments indicate the active sites of GH18 chitolectin chitotriosidase. 
active site (shown in bold in Fig. 1) involved in the enzymatic activity of chitinase belonging to the GH18 group with other sequences (Henrissat and Bairoch, 1993; Korb et al., 2012; Lu et al., 2002; Sharma et al., 2011; Terwisscha van Scheltinga et al., 1996; Thomas et al., 2000). KC477099 have 17 active amino acid sites in the GH18 chitolectin chitotriosidase (https://www.ncbi.nlm.nih.gov/Structure/cdd/cddsrv.cg i?hslf=1\&uid=119351\&\#seqhrch), which is the family with the most specific hits to KC477099 (Fig. 1). Among the active sites, 16 sites are located in the $\beta$ strands (Fig. 1).
The amino acid sequence of motif II is FDGLDIDWEYP, which is part of the amino acid sequence of KC477099. The Asp-Trp-Glu site in motif II has a significant role in the enzymatic activity of GH18 (Henrissat and Bairoch, 1993; Huang et al., 2010; Synstad et al., 2004; Zhang et al., 2002). Glu ${ }^{158}$ in KC477099 may be involved in the cleavage of glycosidic bonds through protonation as a proton donor in the GH18 enzymatic activity (Sinnott, 1990). The switching of $\mathrm{Glu}^{158}$ to another amino acid significantly reduces its enzymatic activity (Henrissat and Bairoch, 1993). Asp ${ }^{156}$ has been suggested as an electrostatic
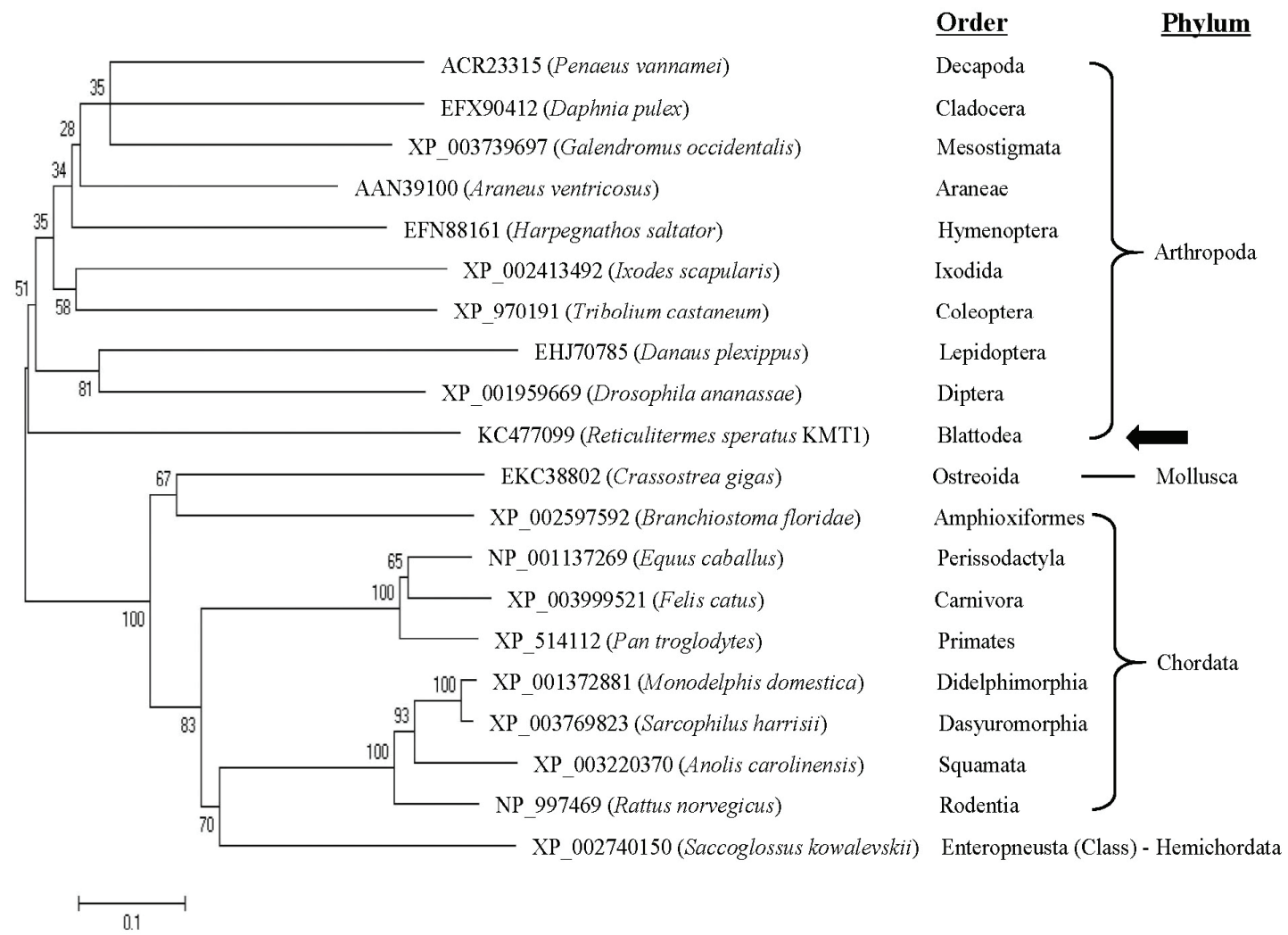

Fig. 2. Phylogenetic analysis of KC477099 from R. speratus KMT001 and chitinase from 19 strains from a protein BLAST search at the National Center for Biotechnology Information. A neighbor-joining method with a bootstrap of 1,000 replications was used. The order and phylum of each strain are listed on the right side of the figure. KC477099 is indicated using a black arrow. Saccoglossus kowalevskii class is listed because it has not been assigned to an order. 
stabilizer in the transition state and is less involved in the enzymatic activity of GH18 than Glu ${ }^{158}$ (Huang et al., 2010; Synstad et al., 2004). Glu ${ }^{154}$ is involved in the ionization state of $\mathrm{Glu}^{158}$ and affects the $p K$ values of $\mathrm{Glu}^{158}$ and $\mathrm{Asp}^{156}$ (Henrissat and Bairoch, 1993). An additional amino acid in motif II that affects the enzymatic activity of GH18 is $\operatorname{Trp}^{157}$. $\operatorname{Trp}^{157}$ maintains the abnormal $p K$ values of other amino acids during enzymatic activity. It has an important role in the extension of chitinase activity within an alkaline $\mathrm{pH}$ range (Zhang et al., 2002).

\subsection{Phylogenetic analysis}

To investigate the evolutionary relationships between genes, we analyzed the phylogeny of the 20 genes shown in Fig. 1 (Fig. 2). KC477099 was grouped in the phylum Arthropoda with the Decapoda, Mesostigmata, Araneae, Hymenoptera, Lepidoptera, and Ixodide. The biological function of chitinase in the phylum Arthropoda is the digestion of food, decomposition of the exoskeleton in ecdysis, and defense of the body against toxicity (Henrissat and Davies, 1997; Merzendorfer and Zimoch, 2003).

The phylum Mollusca, order Ostreoida, phylum Hemichordata class Enteropneusta, and phylum Chordata, including orders Perissodactyla, Carnivora, Primates, Rodentia, Squamata, Didelphimorphia, and Dasyuromorphia, were grouped in one of the main branches. All of them were identified as chitotriosidase and AMCase in GH18. Chitotriosidase was the first chitinase found in humans, and AMCase is chitotriosidase expressed in an acidic condition (Reardon and Farber, 1995). In the group of the phylum Arthropoda, the KC477099 branch is separated at the earliest stage. This phylogenetic analysis confirms that the putative chitinase KC477099 of $R$. speratus KMT001 is unique from other reported chitinases in the phylum Arthropoda and has low homology in the BLAST search.

\section{CONCLUSION}

The transcriptomic analysis of $R$. speratus KMT001 identified a putative chitinase gene, KC477099, which includes the complete ORF of the chitinase gene with the consensus amino acids of GH18. The homology between KC477099 and the sequence with the highest homology score was A. ventricosus at $47 \%$. Multiple sequence alignment identified two conserved motifs in GH18, and the active amino acid sites Asp ${ }^{156}-\operatorname{Trp}^{157}$ $\mathrm{Glu}^{158}$. Phylogenetic analysis showed that KC477099 is grouped with other chitinases of the phylum Arthropoda, but its branch separates at the earliest stage. All of the analyses suggest that KC477099 is a new termite-derived chitinase gene of $R$. speratus KMT001. This new chitinase can provide an important biological target for the control of termites.

\section{ACKNOWLEDGMENT}

This study was carried out with the support of 'R\&D Program for Forest Science Technology (Project No. 2013070E10-1819-AA03)' provided by Korea Forest Service (Korea Forestry Promotion Institute).

\section{REFERENCES}

Arakane, Y., Muthukrishnan, S. 2010. Insect chitinase and chitinase-like proteins. Cellular and Molecular Life Sciences 67(2): 201-216.

Aronson, N.N., Blanchard, C.J., Madura, J.D. 1997. Homology modeling of glycosyl hydrolase family 18 enzymes and proteins. Journal of Chemical Information and Computer Sciences 37(6): 9991005.

Badariotti, F., Thuau, R., Lelong, C., Dubos, M.-P., Favrel, P. 2007. Characterization of an atypical family 18 chitinase from the oyster Crassostrea gigas: Evidence for a role in early development 
and immunity. Developmental \& Comparative Immunology 31(6): 559-570.

Bartnicki-Garcia, S. 1968. Cell wall chemistry, morphogenesis, and taxonomy of fungi. Annual Review of Microbiology 22: 87-108.

Brydon, L.J., Gooday, G.W., Chappell, L.H., King, T.P. 1987. Chitin in egg shells of Onchocerca gibsoni and Onchocerca volvulus. Molecular and Biochemical Parasitology 25(3): 267-272.

Bussink, A.P., Speijer, D., Aerts, J.M., Boot, R.G. 2007. Evolution of mammalian chitinase(-like) members of family 18 glycosyl hydrolases. Genetics 177(2): 959-970.

Cho, M.J., Shin, K., Kim, Y.-K., Kim, Y.-S., Kim, T.-J. 2010. Phylogenetic analysis of Reticulitermes speratus using the mitochondrial cytochrome C oxidase subunit I gene. Journal of the Korean Wood Science and Technology 38(2): 135-139.

Fukamizo, T., Speirs, R.D., Kramer, K.J. 1985. Comparative biochemistry of mycophagous and non-mycophagous grain beetles. Chitinolytic activities of foreign and sawtoothed grain beetles. Comparative Biochemistry and Physiology BBiochemistry \& Molecular Biology 81(1): 207-209.

Fukamizo, T. 2000. Chitinolytic enzymes: catalysis, substrate binding, and their application. Current Protein \& Peptide Science 1(1): 105-124.

Guan, Y.Q., Chen, J.M., Li, Z.B., Feng, Q.L., Liu, J.M. 2011. Immobilisation of bifenthrin for termite control. Pest Management Science 67(2): 244-251.

Hadi, Y.S., Massijaya, M.Y., Zaini, L.H., Abdillah, I.B., Arsyad, W.O.M. 2018. Resistance of methyl methacrylate-impregnated wood to subterranean termite attack. Journal of the Korean Wood Science and Technology 46(6): 748-755

Han, J.H., Lee, K.S., Li, J., Kim, I., Je, Y.H., Kim, D.H., Sohn, H.D., Jin, B.R. 2005. Cloning and expression of a fat body-specific chitinase cDNA from the spider, Araneus ventricosus. Comparative
Biochemistry and Physiology - Part B: Biochemistry \& Molecular Biology 140(3): 427-435. Henrissat, B., Bairoch, A. 1993. New families in the classification of glycosyl hydrolases based on amino acid sequence similarities. Biochemical Journal 293 (Pt 3): 781-788.

Henrissat, B., Davies, G. 1997. Structural and sequencebased classification of glycoside hydrolases. Current Opinion in Structural Biology 7(5): 637-644.

Henrissat, B. 1999. Classification of chitinases modules. EXS 87: 137-156.

Huang, Q.S., Yan, J.H., Tang, J.Y., Tao, Y.M., Xie, X.L., Wang, Y., Wei, X.Q., Yan, Q.H., Chen, Q.X. 2010. Cloning and tissue expressions of seven chitinase family genes in Litopenaeus vannamei. Fish and Shellfish Immunology 29(1): 75-81.

Husen, T.J., Kamble, S.T. 2013. Delayed toxicity of two chitinolytic enzyme inhibitors (psammaplin A and pentoxifylline) against eastern subterranean termites (Isoptera: Rhinotermitidae). Journal of Economic Entomology 106(4): 1788-1793.

Husen, T.J., Kamble, S.T., Stone, J.M. 2015. Effect of pentoxifylline on chitinolytic enzyme activity in the eastern subterranean termite (Isoptera: Rhinotermitidae). Journal of Entomological Science 50(4): 295-310.

Kawada, M., Hachiya, Y., Arihiro, A., Mizoguchi, E. 2007. Role of mammalian chitinases in inflammatory conditions. The Keio Journal of Medicine 56(1): 21-27.

Kim, S.H., Chung, Y.J. 2017. Ingestion toxicity of fipronil on Reticulitermes speratus kyushuensis (Isoptera: Rhinotermitidae) and its applicability as a termite bait. Journal of the Korean Wood Science and Technology 45(2): 159-167.

Korb, J., Hoffmann, K., Hartfelder, K. 2012. Molting dynamics and juvenile hormone titer profiles in the nymphal stages of a lower termite, Cryptotermes secundus (Kalotermitidae)--signatures of develop- 
mental plasticity. Journal of Insect Physiology 58(3): 376-383.

Kramer, K.J., Koga, D. 1986. Insect chitin - physical state, synthesis, degradation and metabolicregulation. Insect Biochemistry 16(6): 851-877.

Kramer, K.J., Muthukrishnan, S. 1997. Insect chitinases: Molecular biology and potential use as biopesticides. Insect Biochemistry and Molecular Biology 27(11): 887-900.

Liu, N., Zhang, L., Zhou, H., Zhang, M., Yan, X., Wang, Q., Long, Y., Xie, L., Wang, S., Huang, Y., Zhou, Z. 2013. Metagenomic insights into metabolic capacities of the gut microbiota in a funguscultivating termite (Odontotermes yunnanensis). PLOS ONE 8(7): e69184.

Lu, Y., Zen, K.C., Muthukrishnan, S., Kramer, K.J. 2002. Site-directed mutagenesis and functional analysis of active site acidic amino acid residues D142, D144 and E146 in Manduca sexta (tobacco hornworm) chitinase. Insect Biochemistry and Molecular Biology 32(11): 1369-1382.

Matsui, T., Tokuda, G., Shinzato, N. 2009. Termites as functional gene resources. Recent Patents on Biotechnology, 3(1): 10-18.

Merzendorfer, H., Zimoch, L. 2003. Chitin metabolism in insects: structure, function and regulation of chitin synthases and chitinases. Journal of Experimental Biology 206(24): 4393-4412.

Mishra, S.C., Sensarma, P.K. 1981. Chitinase activity in the digestive-track of termites (Isoptera). Material Und Organismen 16(2): 157-160.

Mun, S.P., Nicholas, D.D. 2017. Effect of proanthocyanidin-rich efrom Pinus radiata bark on termite feeding deterrence. Journal of the Korean Wood Science and Technology 45(6): 702-727.

Nei, M., Saitou, N. 1987. The neighbor-joining method: a new method for reconstructing phylogenetic trees. Molecular Biology and Evolution 4(4): 406-425. Park, H.-S., Ham, Y., Ahn, H.-H., Shin, K., Kim, Y.-S.,
Kim, T.-J. 2014. A new $\alpha$-amylase from Reticulitermes speratus KMT1. Journal of the Korean Wood Science and Technology 42(2): 149-156.

Rathore, A.S., Gupta, R.D. 2015. Chitinases from bacteria to human: Properties, applications, and future perspectives. Enzyme Research 2015(Article ID 791907): 8.

Reardon, D., Farber, G.K. 1995. The structure and evolution of alpha/beta barrel proteins. The FASEB Journal 9(7): 497-503.

Renkema, G.H., Boot, R.G., Au, F.L., DonkerKoopman, W.E., Strijland, A., Muijsers, A.O., Hrebicek, M., Aerts, J.M. 1998. Chitotriosidase, a chitinase, and the 39-kDa human cartilage glycoprotein, a chitin-binding lectin, are homologues of family 18 glycosyl hydrolases secreted by human macrophages. European Journal of Biochemistry 251(1-2): 504-509.

Reynolds, S.E., Samuels, R.I. 1996. Physiology and biochemistry of insect moulting fluid. Advances in Insect Physiology 26: 157-232.

Sandoval-Mojica, A.F., Scharf, M.E. 2016. Silencing gut genes associated with the peritrophic matrix of Reticulitermes flavipes (Blattodea: Rhinotermitidae) increases susceptibility to termiticides. Insect Molecular Biology 25(6): 734-744.

Sharma, N., Sharma, K.P., Gaur, R., Gupta, V.K. 2011. Role of chitinase in plant defense. Asian Journal of Biochemistry 6(1): 29-37.

Sinnott, M. 1990. Catalytic mechanisms of enzymic glycosyl transfer. Chemical Reviews 90(7): 1171-1202.

Synstad, B., Gaseidnes, S., Van Aalten, D.M., Vriend, G., Nielsen, J.E., Eijsink, V.G. 2004. Mutational and computational analysis of the role of conserved residues in the active site of a family 18 chitinase. European Journal of Biochemistry 271(2): 253-262. Taira, T., Ohnuma, T., Yamagami, T., Aso, Y., Ishiguro, 
M., Ishihara, M. 2002. Antifungal activity of rye (Secale cereale) seed chitinases: the different binding manner of class I and class II chitinases to the fungal cell walls. Bioscience, Biotechnology, and Biochemistry 66(5): 970-977.

Tamura, K., Dudley, J., Nei, M., Kumar, S. 2007. MEGA4: Molecular evolutionary genetics analysis (MEGA) software version 4.0. Molecular Biology and Evolution 24(8): 1596-1599.

Terwisscha van Scheltinga, A.C., Hennig, M., Dijkstra, B.W. 1996. The $1.8 \AA$ resolution structure of hevamine, a plant chitinase/lysozyme, and analysis of the conserved sequence and structure motifs of glycosyl hydrolase family 18. Journal of Molecular Biology 262(2): 243-257.

Thomas, C.J., Gooday, G.W., King, L.A., Possee, R.D. 2000. Mutagenesis of the active site coding region of the Autographa californica nucleopolyhedrovirus
chiA gene. Journal of General Virology 81(Pt 5): 1403-1411.

van Eijk, M., van Roomen, C.P., Renkema, G.H., Bussink, A.P., Andrews, L., Blommaart, E.F., Sugar, A., Verhoeven, A.J., Boot, R.G., Aerts, J.M. 2005. Characterization of human phagocyte-derived chitotriosidase, a component of innate immunity. International Immunology 17(11): 1505-1512.

Zhang, H., Huang, X., Fukamizo, T., Muthukrishnan, S., Kramer, K.J. 2002. Site-directed mutagenesis and functional analysis of an active site tryptophan of insect chitinase. Insect Biochemistry and Molecular Biology 32(11): 1477-1488.

Zhu, K.Y., Merzendorfer, H., Zhang, W., Zhang, J., Muthukrishnan, S. 2016. Biosynthesis, turnover, and functions of chitin in insects. Annual Review of Entomology 61(1): 177-196. 